\title{
Love as a linguacultural space (on the basis of paroemias in the English, Welsh, Gaelic and Scots languages)
}

\author{
Yuliya Yevgrafova ${ }^{1,{ }^{*}}$, Olga Gorbacheva ${ }^{1}$, Kseniya Skripnik $^{1}$, Olga Fedorovich $^{1}$ \\ ${ }^{1}$ Moscow Region State University, 10A, Radio Str., 105005, Moscow, Russia
}

\begin{abstract}
The present work explores the feeling of love in linguistic world pictures of different ethnic groups that comprise a single nation. The authors attempted to describe this feeling as a linguacultural space and define its aspects, both universal and nationally specific. The methodology of the research encompassed a comparative method, continuous sampling method, method of structural and semantic analysis and method of contextual analysis. The paper offers the analysis of paroemiological units in English, Welsh, Scottish Gaelic and Scots languages. Qualitative and quantitative characteristics of representation of the concept of Love were defined. Semantic structure of this word was revealed. There were described nationally specific features of representation of "man's" matter when structuring Love within the framework of linguistic culture in the linguistic world picture. As the result of the study, a generalized scheme of the linguacultural space of Love is revealed at the level of a nation's linguistic picture of the world, and the idioethnic one at the level of an individual ethnic group. Certain standards and stereotypes contained in this linguacultural space are distinguished as well.
\end{abstract}

\section{Introduction}

In the age of globalization, different ethnic groups converge rapidly. Certain elements of various cultures gain global popularity. Such internationalization makes us reconsider and systemize the customary ideas, stereotypes and images that we have about each other and the world, particularly such "familiar" and "conceivable" phenomena as love. Love can be attributed to universal feelings, since, at the biological level, it springs up in a certain area of human brain. It is accompanied by a number of psychological processes and has its own mechanism of action, which is culturally universal. Only being verbalized through a language, it acquires certain idioethnic features, which can be traced in a linguistic world picture of a single nation formed by several ethnic groups. Such comparison will allow "removing" all idioethnic layers and reveal the core that is common and typical in the views and ideas that are "transmitted" by different linguistic cultures that make up a single nation.

An example to consider is the linguistic picture of the world (LPW) of British people. The history of the British Isles is quite hard, and unfortunately, today it is often considered

* Corresponding author: taniasemina@gmail.com 
only from the English perspective, without taking into account the ethnic groups of Wales, Scotland and Ireland, although people currently living in these territories still do not feel that they are a part of the Anglo-Saxon world. Besides English, which is the official language of Great Britain, other national languages are still used in its territory: Scots, Welsh, Gaelic (Irish dialect, Scottish dialect) and Cornish. Therefore, the British LPW consists of languages belonging to historical population of Great Britain: English, Welsh, Gaelic (Irish and Scottish dialects) and Scots. Ethnic cultures of native speakers of these languages have not merged into one culture despite their common history, each one has its own nationally specific ideas and stereotypes (The Cornish language is not considered in the present paper, since there have remained very few native speakers by now, Irish Gaelic and Scottish Gaelic are considered as a single dialect continuum). The objective of the present study is to distinguish similarities and differences in ideas that make up the linguistic pictures of the world (LPW) of the languages listed above. In order to achieve this goal, paroemiological units were analyzed as carriers of nationally specific stereotypes. The paroemiological scope of these languages served as proceedings for the research, since it, being complete, reflects the ethnic component of consciousness of those people who has composed it. Of course, modern British linguistic culture is still experiencing certain dynamics in the structure of the paroemiological basis, but in order to avoid the recency effect, we will limit the scope of dictionaries of proverbs to those edited in the end of the 19 th and the beginning of the 20th century, so that the research would be performed and the patterns would be defined based on already finished processes.

\section{Methods}

Methods of investigating the empirical material are determined by the goal, tasks, object and subject of this work. The comparative method was used for systemic comparison of complete lexical units belonging to different languages in order to detect structural and semantic differences. The method of continuous sampling drawn from lexicographic publications and scientific periodicals was used to select empirical material and to find differences in ways of using a concept in different languages. The method of structural and semantic analysis of lexical units was used to identify general and distinctive properties and characteristics of lexical structures in order to further work out their objective typology. The method of contextual analysis helped find semantic diversities in semantically/lexically alike lexical units.

The material under study is lexical units selected from written lexicographic works [17, 9-14]. Lexical units from books and reference works were also used sporadically.

\section{Results}

Love in a man's picture of the world (MPW) of British people is represented by a diverse set of paroemiological units. For example, they touch upon relationship between a man and a woman who are not married: (English) He who loseth a whore, is a great gainer [2] (Welsh) Cerid chwaer diriad can ni charer [14] A man, who is worthless hated by all, is loved by his sister, (Gaelic) Cha chòir do dhuine a ghràdh 'us' aithne chur a dh-aon taobh [11] Love the one, be friends with the other, a man is given advice on how to behave in order to win a woman's heart: (English) He that woos a maid, must seldom come in her sight, but he that woos a widow must woo her day and night [2], (Welsh) Gwell gwraig o'i chanmawl [14] Praise the woman and you will rise in her estimation, (Gaelic) An uair a chì thu bean oileanach, beir oirre, beir oirre, mur beir thus 'oirre, beiridh fear eile oirre [11] When you see a well-mannered woman, grab her, otherwise the other will do it for you, 
(Scots) Tak a lass wi 'the tear i' her ee [4] Rejected girl is easier to get, even if she once rejected you, 'love' in marriage is also mentioned: (English) Who marries for love without money, has good nights and sorry days [2] (Welsh) Ni cherir yn llwyr oni ddelo'r ŵyr. [13] True love comes with the first grandson, (Gaelic) Socraichidh am pòsadh an gaol [11] Marriage mourns love, (Scots) Naething to be done but draw in your chair and sit down [4] Nothing to be done [with such a bride] but draw in your chair and sit down.

The model of relationship between a man and a woman is not the only one for the representation of love. The material under study contains a clear description of what is inside a man in love: (Welsh) Tra gweno meingan, cipia gusan [14] As long as your beloved beauty smiles, you will love and kiss her, (Gaelic) Fuath giullain, a chiad leannan [11] A man hates his first love, (Scots) A woman's love will traise further than horses [4] A woman's love will draw further than horses. Among other things, negative acts and doings of a man in love are listed: (English) If you can kiss the mistress, never kiss the maid [2], (Gaelic) Teinne chaoran is gaol ghiullan, Cha do mhair iad fada riamh [10] The fire in a peatery and a boy's love never lasted long, (Scots) He got the knights bone off her [9] He seduced her before the wedding.

The examples given above demonstrate that in paroemias of the languages under study, love is verbalized as a response to an impetus that provokes certain actions (reaction turned outside), as well as psychological and spiritual experiences (internal reaction). Thus, it can be concluded that in the British LPW this feeling is represented as a space: internal (IN emotional state) and external (EX 1 - behavior caused by feeling, EX 2 - behavioral reaction to the object of love). The dialectical unity of these spaces makes up a single generalized linguacultural space of 'love' (hereinafter this feeling is put in single quotation marks to designate the linguacultural space, which is not equal to the Russian word), which can be graphically depicted as follows (see Figure 1).

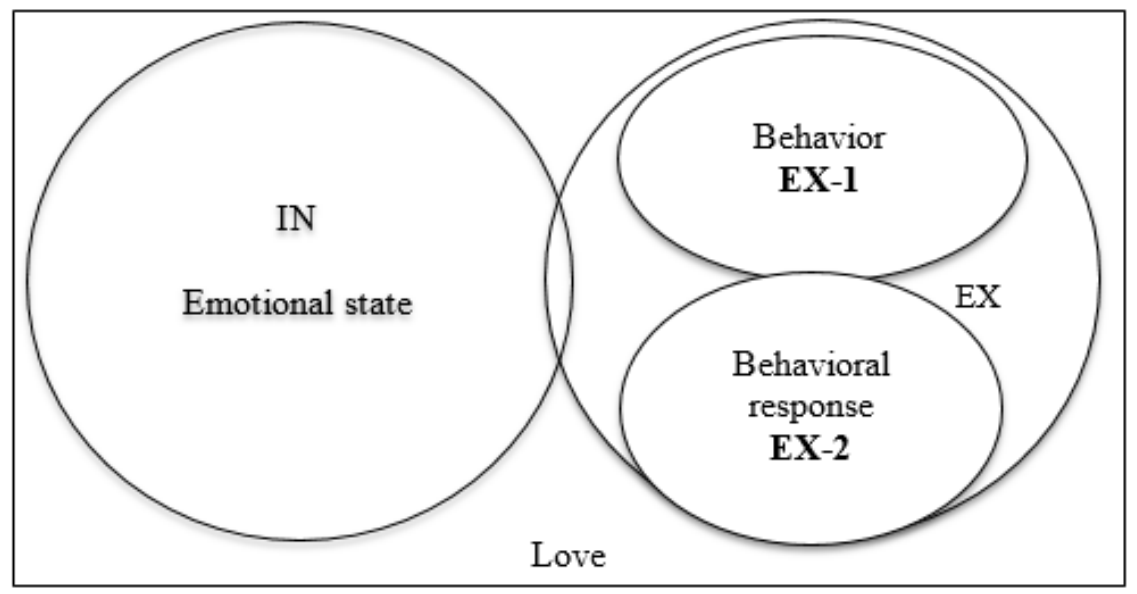

Fig. 1. Linguacultural space of 'love' in MPW (man's picture of the world) of British people.

While not being a basic emotion (i.e. other animals do not experience it), 'love' bears the imprint of a particular linguistic culture. Therefore, each language under study has its generalized space being constructed by a different set of finite points (paroemias), so the diagram presented above would have different numerical extent and, thus, be filled with different "meanings". In the English language, the paroemiological field (the selected corpus of proverbs and sayings) is represented by 52 units, in Welsh - by 12, in Gaelic - by 22, and in Scots - by 17, and their distribution according to "meanings" of internal and external spaces also varies (see table. 1 ). 
Table 1. The numerical extent of the linguacultural space of 'love'.

\begin{tabular}{|c|c|c|c|c|}
\hline $\begin{array}{c}\text { «Meaning»/ } \\
\text { Language }\end{array}$ & English & Welsh & Gaelic & Scots \\
\hline \multicolumn{5}{|c|}{ IN: Emotional state } \\
\hline «Love is blind» & 6 & 1 & 4 & 2 \\
\hline «Love in spite» & 4 & 2 & 0 & 0 \\
\hline $\begin{array}{c}\text { «Love changes } \\
\text { one» }\end{array}$ & 5 & 0 & 0 & 0 \\
\hline \multicolumn{2}{|c|}{ EX-1: Behavior } \\
\hline $\begin{array}{c}\text { «ove without } \\
\text { marriage» }\end{array}$ & 7 & 4 & 7 & 0 \\
\hline $\begin{array}{c}\text { «Love in } \\
\text { marriage» }\end{array}$ & 8 & 2 & 3 & 0 \\
\hline $\begin{array}{c}\text { «Advice on how } \\
\text { to behave» }\end{array}$ & 13 & 3 & 5 & 10 \\
\hline \multicolumn{4}{|c|}{ EX-2: Behavioral responses } \\
\hline «Impermanence» & 4 & 0 & 3 & 4 \\
\hline «Lust» & 5 & 0 & 0 & 1 \\
\hline TOTALLY: & 52 & 12 & 22 & 17 \\
\hline
\end{tabular}

To perform a more accurate comparison of data and identify hidden patterns, the specific gravity of each "meaning" is to be calculated, and next internal and external spaces separately for each language according to the formula:

$$
K=\frac{\text { number of units under analysis fixing this category }}{\text { total number of units under analysis }}
$$

Thus, Figure 1 takes the following form (see Figure 2, 3, 4, 5).

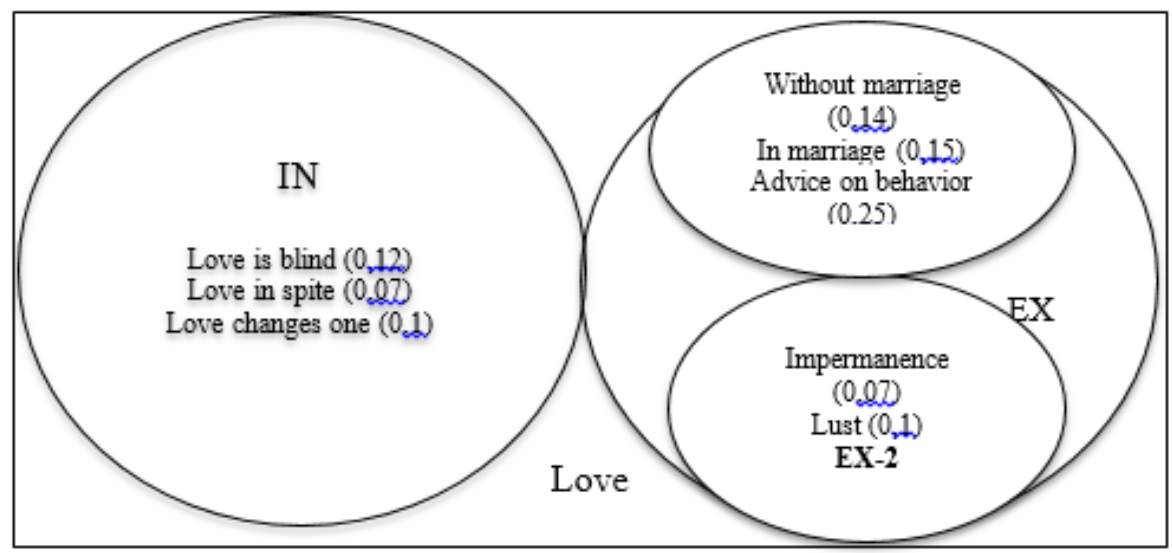

Fig. 2. Linguacultural space of 'love' in MPW of the English language. 


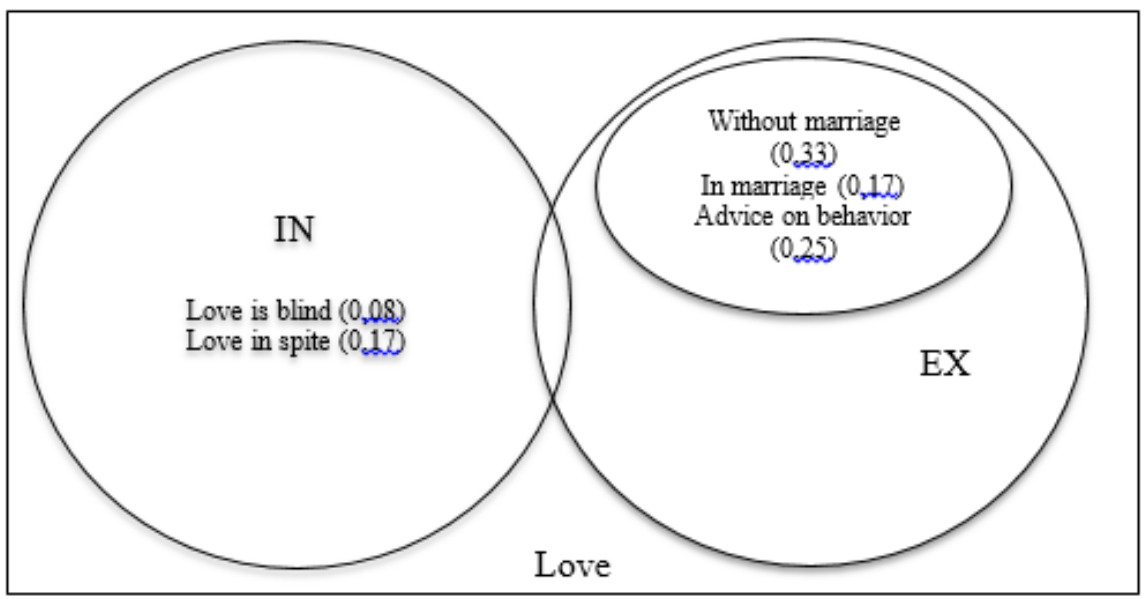

Fig. 3. Linguacultural space of 'love' in MPW of the Welsh language.

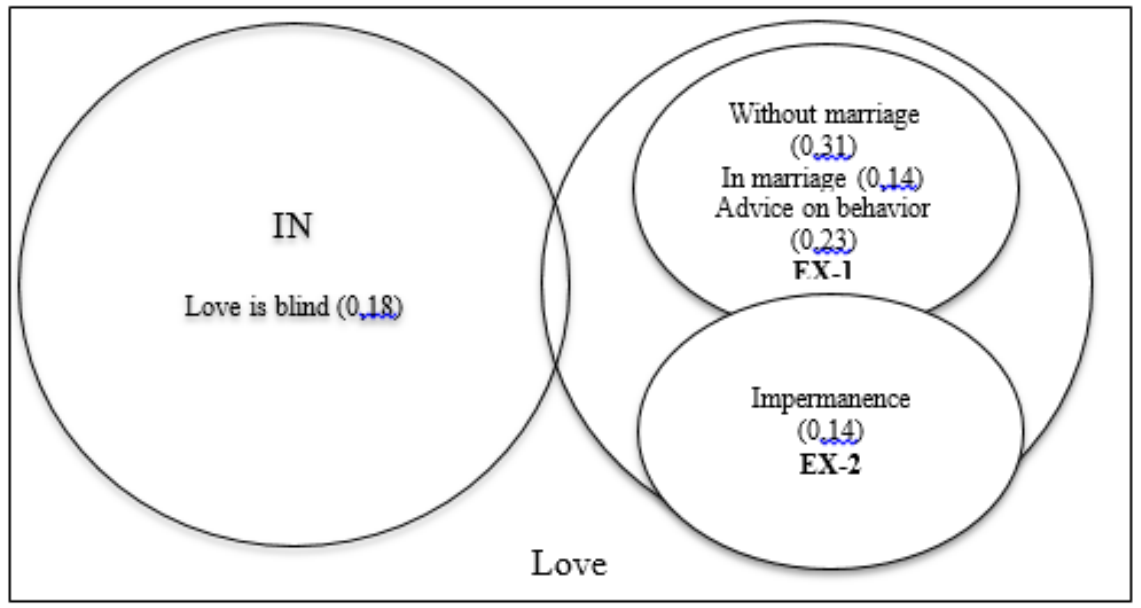

Fig. 4. Linguacultural space of 'love' in MPW of the Gaelic language.

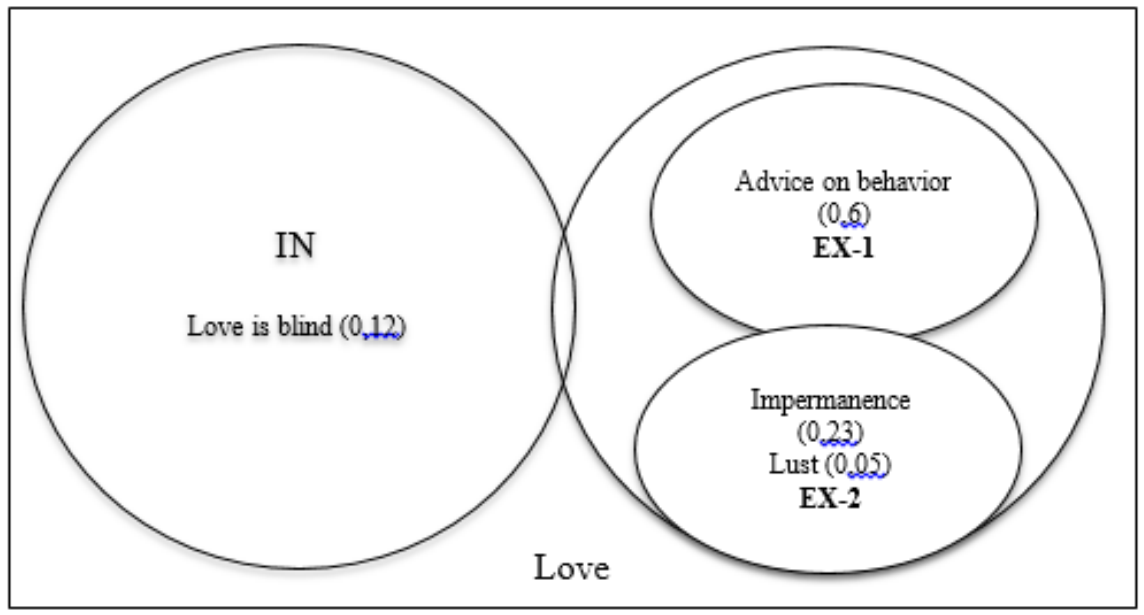

Fig. 5. Linguacultural space of 'love' in MPW of the Scots language. 


\section{Discussion}

The comparison of the data presented in Figure 2 allows singling out one main similarity found in all four languages: the numerical prevalence of the external space (EX-1: Behavior) over the internal one. Also, partially "typical" characteristics are observed in the Gaelic and English languages: in both linguistic cultures, the emotional state ranks the second, while the description of behavioral responses has the least specific weight. Meanwhile in the Scots language behavioral responses are more significant than the emotional state, and in the Welsh language these "meanings" are not referred at all.

Along with "typical" characteristics, linguistic cultures under study have a significant number of idioethnic features, which are manifested not only numerically, but also through a combination of "meanings", which makes an asymmetric representation: the behavior of a man in love in paroemiological units of the English language is aimed at conquering women. However, paroemias that describe love both in marriage and without getting married are less common. In Welsh and Gaelic, by contrast, they speak of an unmarried man's love more often than of a married. In the Scots language, only advice is given on how to court a girl properly. The behavioral reactions of a man in love are not represented in the Welsh language at all, in the Gaelic and Scots languages the meaning "Impermanence" prevail, while in English - "Lust". The emotional state of a man is also represented in different ways. For example, in the Gaelic Scots languages, it is represented by the one meaning "Love is blind", in English there are two more meanings: "Love changes one" and "Love in spite", in Welsh emotional experiences are described through the meaning "Love in spite" and "Love is blind".

When performing the present study, it was noted that "meanings", while forming a linguacultural space, simultaneously reflect certain standards and stereotypes. For example, the paroemiological field of the English language (see Fig. 2a) contains such standards (forms) (the present work uses the classification of love styles proposed by John Alan Lee: 1) eros (spontaneous, enthusiastic, love in the form of honoring), 2) filia (treated as friendship/liking), 3) storge (tender love), 4) agape (sacrificial, ultimate, love for God), 5) ludus (game, sexual interest), 6) mania (obsession, passion), 7) pragma (rational, selfinterested) [8]) of love: eros A lover's soul lives in the body of his mistress [2]. pragma Marry first, and love will follow [1] In Welsh, love is represented in the form of ludus Tra gweno meingan, cipia gusan [14] As long as your beloved beauty smiles, you will kiss her, mania Mal llyfu mel oddiar ddrain [14] Loving a woman full of contempt is the same as licking honey from thorns, filia: Cerid chwaer diriad can ni charer [11] A man, who is worthless and hated by everyone, is loved by his sister. The Gaelic language has such standards of love as ludus Cho teth ri gaol seòladair. [11] Hot as the love of a sailor, and mania Teine chaoran 'us gaol ghiul'an, [3] A boy's love is like fire in the peatary. Love in the Scottish language is represented by the following standards: eros A woman's love will traise further than horses [4], pragma Naething to be done but draw in your chair and sit down [3]. Interesting fact that the standards mentioned above are observed only in the internal space, almost none of them can be found in the external space.

In the external space, stereotypical ideas of behavior are captured. For example, in the English language, love is of special significance: He that does not love a woman, sucked a sow [6], lover is haunted by obsessive thoughts: A lover's soul lives in the body of his mistress [2]., there is a fever of feelings: He that cannot hate cannot love [5], surge of energy: He that has love in his breast, has spurs in his sides [1], a lover is emotionally dependent: A man has choice to begin love, but not to end it [6], barriers and misfortunes only heighten his passion: Nineteen naysays o' a maiden are a ha' $f$ grant [3], there are also some paroemias about sexual relationship: He that woos a maid, must feign, lie and flatter, But he that woos a widow, must down with his breeches, and at her [3], the fleetingness of 
love is also referred to: Lad's love's a busk of broom, hot awhile and soon done [3]. In the Welsh language, stereotypes of man's behavior are not as numerous as in English: only typical representations of praising the subject of passion are found there: Gwell gwraig o'i chanmawl [14]. By praising a woman, you will increase her value, the fever of feelings is also represented: A garer neu gaseir a welir o bell [13]. The lover is seen from afar, and mood swings: Nid siomedigaeth ond gwraig [14]. It's not a woman, it's disappointment. The Gaelic language also has a stereotype that a man in love experiences a fever of feelings: Fuatli giullain, a chiad leannan [4]. A boy hates his first love afterwards, surge of energy: Far nach ionmhuinnduine, is ann a'sfhasa'éigneachadh [1]. You cannot prevail against a lover, emotional dependence: Mairg léigeas a rún le mnaoi [12]. Oh madman, woe to you who have trusted a woman, the fleetingness of feelings is also indicated: Teinne chaoran is gaol ghiullan, Cha do mhair iad fada riamh [10]. Peataries and boy's love never live long. Stereotypes existing in the Scottish language touch upon sexual relationship between a man and a woman: He got the knights bene off "her [9]. He has already "laid her", fleetingness of love: There are mair maidens than maukins. [4] He lost one, he will find another very soon, and it is also indicated that misfortunes intensify passion: Nineteen naysay o 'a maiden is half a grant [2]. Nineteen "no" of a girl is a half of "yes".

Highlighted idioethnic standards and stereotypes help find common ground in the representation of 'love' in the British MPW: "typical" standards of honoring love (eros), love of sexual attraction (ludus), passionate love and "typical" stereotypes of a man in love (obstacles and misfortunes intensify passion, which entails the fever of feelings and the surge of energy that fade away very fast, sexual relationship without getting married/before marriage is also described).

\section{Conclusion}

All of the above allows concluding that all the languages under study, represent love in the traditional biological and psychological sense, i.e. in the form of a feeling and attitude arising as a response to an incentive or without an incentive. Therefore, 'love' may be described as a two-dimensional linguacultural space represented by the "internal - external" binarity. The internal space is built of an emotional state, while the external is divided into the behavior conditioned by a feeling and a behavioral response to an object of love. The boundary between the internal and external spaces is fuzzy and lies in the human mind. Moreover, the study on the paroemiological field of languages under consideration showed that 'love' is also a feeling of a social nature: being depicted in paroemias, the instincts of homo sapiens are "civilized" and ritualized, and take the form of stereotypes and standards. Moreover, in the linguacultural space of 'love', the standards are verbalized within the internal space, while stereotypes - within the external spaces. Similarities and interconnections of the ideas of love in the languages understudy can be explained by the common historical line of their speakers, as well as the universal biological grounds of psychological processes. The main prerequisite of the existence of nationally specific features in the representation of love in the linguistic cultures under study is the desire to confirm their national identity and protect their group values.

Further research prospects consist in consideration on the female picture of the world and in study on corresponding paroemiological units. In addition, it seems reasonable to consider other linguistic cultures that make up a single nation, just like the cultures of the British Isles. In conclusion, it would be worth noting that studies on idioethnic features of a linguistic picture of the world of a nation that consists of several ethnic groups preserving their identity, helps clarify and prevent difficulties arising in the process of intercultural communication between representatives of ethnic groups, as well as of native speakers of other languages. 


\section{References}

1. G.L. Apperson, M.H. Manser, Dictionary of proverbs (Ldn, Wordsworth Editions, 2007)

2. H.G. Bohn, A hand-book of proverbs (Ldn, Bohn, 1855)

3. H.G. Bohn, J. Ray, A hand-book of proverbs: comprising an entire republication of Ray's collection of English proverbs, with his additions from foreign languages, and a complete alphabetical index (Ldn, G. Bell and sons, 1860)

4. A. Cheviot, Prverbs, proverbial expressions and popular rhymes of Scotland (Ldn, Paisley, 1896)

5. V. Gratian, Proverbs (Sterling Publishers Pvt. Ltd, 1998)

6. W.C. Hazlitt, English proverbs and proverbial phrases (Ldn, John Russell Smith, 1869)

7. A. Hislop, Proverbs of Scotland with explanatory and illustrative notes and a glossary. Rev. and suppl (Edinburg, Alexander Hislop \& Company,1868)

8. John Alan Lee, Bulletin of Personality and Social Psychology 3(2), 173 (1977) doi: $10.1177 / 014616727700300204$

9. J. Kelly, A complete collection of Scottish proverbs explained and made intelligible to the English reader (Lnd, Rodwell \& Martin, 1818)

10. T.D. Macdonald, Gaelic proverbs and proverbial sayings (E. Mackay, 1926)

11. M.A. Nicolson, A collection of Gaelic proverbs and familiar phrases: based on Macintosh's collection. $2^{\text {nd }}$ ed (Edinburgh, Maclachlan and Stewart, Ldn, Simpkin, Marshall \& Co, 1882)

12. T.F. O'Rahilly, A Miscellany of Irish Proverbs (Dublin, The Talbot Press,1922)

13. T.A. Roberts, The Proverbs of Wales: A Collection of Welsh Proverbs, with English Translations (Penmaenmawr, T.R. Robets, 1885)

14. H.H. Vaughan, British reason in English rhyme (Ldn, Kegan Paul, Trench \& Co, 1889) 